Chapter I

Between the Political and the Particular 



\title{
Jihadist and Far-Right Extremism: Subjectivity, Embodiment and Imaginaries of Violence
}

\author{
Kevin McDonald
}

\section{Radicalisation: A Contested Concept}

Over the past 15 years a new kind of violence has emerged in the democratic societies of Europe, North America and the Pacific, from attacks on the transport systems in London and Madrid in 2005, to other forms of extreme violence including the killing of over 180 people by a jihadist commando group in Paris in November 2015. During the period 2011 to 2017 some 5,000 Europeans travelled to Syria to join jihadist groups. While travel to Syria to join jihadist groups experienced a dramatic reduction following the military defeats experienced by the Islamic State and the loss of its capital, Raqqa, in October 2017, radicalised violence has nonetheless continued in Europe. In the final three months of 2019 four police officers were murdered by a colleague at Police Headquarters in Paris (Vincent and Cahpuis 2019); two passers-by were murdered during an attempted massacre at a Synagogue in Halle in Germany (Koehler 2019); and two participants were killed while attending a prison education event in London (Guardian staff, 2019). In Paris and London, the killers were supporters of jihadist violence, while in Halle the suspected killer live-streamed the attack to an online gaming platform, claiming it as an action in defence of the white race (Koehler 2019).

It was during the past 15 years that the concept of 'radicalisation' emerged in its current form, becoming increasingly widespread following the publication of Radicalization in the West: the Homegrown Threat by the New York Police Department in 2007 (Bhatt and Silber 2007). This was an attempt to understand what was seen to be a break with organised terrorism that had been present in Europe and North America during the 1970s and into the 1980s. The violence that emerged from the mid-2000s was often improvised, undertaken by friends, by family-based networks, or by individuals. This was very different from the groups that emerged out of the collapsing student movement in the 1970s: the Weather Underground in the United States, the Red Brigades in Italy, the Red Army Faction in Germany, and the Japanese Red Army (for an overview of these groups see Mc- 
Donald 2013). These militarised groups that emerged as the radical student movement collapsed were understood as expressions of 'clandestine political violence' (Della Porta 2013), the product of a mutation of a social movement or conflict. A key to the analysis of these groups was a process of 'competitive escalation' (Della Porta 2013), where increasingly violent demonstrations were met by, or a response to, increasingly violent policing, with activist groups coming to understand themselves as 'at war' with the state, in particular the police, and modelling themselves as 'urban guerrillas' inspired by romantic images of Cuban or Palestinian fighters. Almost all the members of the groups that emerged in the 1970s were former student activists, who, frustrated at what they believed to be the impossibility of radical social change, gradually came to embrace clandestinity and political violence. This was not the case with the jihadist violence that became increasingly evident in Europe from the mid-2000s, where those involved had little or no previous experience of activism.

In its first iteration, 'radicalisation' as an explanatory paradigm was an expression of strain theory, where young second generation immigrants find themselves caught 'in between' the world of their parents that is no longer intelligible, and a new society they experience as exclusionary or stigmatising. Not surprisingly, this approach to radicalisation was first formulated in the United States, drawing on North American approaches to migration, social integration and theories of the rise of gangs. Young people according to this approach were in experiences of uncertain transition, and it was the failure of European society to achieve the integration of second-generation migrants that was seen as the ultimate cause of radicalisation - something that emerged where social identity was in crisis, leading to an increasingly religious search for self (Bhatt and Silber 2007). It is important to note that this understanding of generation and integration was framed by a broader cultural context shaped by theories of 'clash of civilizations', particularly influential in the period following the collapse of the Berlin Wall (Huntington 1996). In its initial formulation, radicalisation was conceived as a linear process, leading from vulnerability, through indoctrination, to 'jihadization' and then 'attack'. Thus framed, radicalisation was understood as a process where failure of social integration exacerbated religious identity-seeking to the point where this became violent.

Understood in this way, the term 'radicalisation' has been hotly contested. While it frames major public policy initiatives such as the European Radicalisation Awareness Network or national programmes such as Prevent in the United Kingdom, its critics argue that this framework has embedded within it an opposition between 'old terrorism' intelligible in political terms and a 'new terrorism' with its origins in Islamist theology. 
Critics argue that the use of 'radicalisation' as a framework has led to the creation of 'suspect communities' and to a failure to understand the political origins of the conflicts and fault lines generating contemporary violence (Kundnani 2012). From this perspective, radicalisation is understood as a dimension of what is claimed to be a 'global rise of religious violence' (Juergensmeyer 2017). Largely located within disciplines which had previous engagement with terrorism, in particular International Relations and Security Studies, this conceptualisation drew on previous models of 'propaganda' that had emerged during the Cold War, reframing this within a paradigm of 'narrative' and calling for 'counter narrative' as a response. This appeared to capture the importance of images, videos and digital media in the jihadist radicalisation of young people that became increasingly evident with the first departures to Syria in 2011. Just as radicalisation was seen to be something done to a person, this model of communication was understood as a one-way transmission of messages, directed in particular to those vulnerable to recruitment.

There are several problems with this understanding of 'radicalisation'. Firstly, it unifies experiences and pathways that are very different, from the high performing school student to the drug dealer, while separating 'radicalised' violence from other violence that arguably demonstrates significant similarities, such as that of school shooters or its recent development as incel-violence ${ }^{1}$. Secondly, while highlighting the importance of digital communication, early approaches to radicalisation understood such communication as indoctrination or recruitment, drawing on earlier understandings of propaganda as a system of one-way communication. While alert to the importance of communication, there was initially little understanding of the 'social' and 'affective' nature of digital communication when compared to older models of 'indoctrination'. Thirdly, while the emphasis on vulnerability and strain allowed scope for policies based on prevention and safeguarding, it offered little insight into the forms of agency involved in radicalisation, and as a result, little insight into the kinds of agency involved in experiences of disengagement. Within this paradigm, radicalisation came to be understood as something done to a vulnerable young person, while equally, deradicalisation is something done to a young person.

1 'Incels' are men who consider themselves to be rejected by women, and thus 'involuntary celebates'. The first incel massacre, aimed at female students of the University of California, Santa Barbara, took place in May 2014. For an overview see Beauchamp 2019. 
This chapter presents research that sets out to understand radicalisation as agency and experience, and in the process begins to consider what we can learn from a comparative exploration of radicalisation in Europe and Asia. The first part of the chapter is based on interviews and focus groups with 50 members of jihad supporting groups in the United Kingdom together with an analysis of the social media posts of 30 young people who travelled to Syria to join jihadist groups between 2013 and 2017 (this is detailed in McDonald 2018). The second part introduces research on experiences of far-right extremism currently emerging in Europe, linking these to broader networks in particular associated with online digital forums based in North America. From these cases, several themes are highlighted in terms of comparison between the European experience and that of Asia.

\section{Jihadist Radicalisation}

Recent research has underlined the extent to which radicalisation is a social process. What sort of social worlds does this take place in, and how can we approach radicalisation as embodied, imaginary and relational? The early approaches to radicalisation and violence were largely framed within a binary of radicalised or not radicalised, violent or not violent. However my research suggests that we can distinguish between very different kinds of radicalisation, each framing different imaginaries and practices of violence. While aspects overlap, we can distinguish three different 'experiences' or 'pathways' of radicalisation. The first of these centres on 'us', and is constructed around the axes of us/them, inclusion/exclusion, order/disorder, or purity/impurity. Across these we encounter affective states organised around anxiety and the social construction of disgust, as well as the search for security in a structured and closed community. A second experience of radicalisation centres on 'you', and is built around an affirmation of power, with significant debt to imaginaries of gaming and to an experiential structure of the hidden and the revealed, the visible and invisible, winners and losers. A third focuses on experiences of 'I', where we encounter practices of individuation such as purification of the self, sacrifice of the self, and experiences of the sublime where a heightened sense of awe and enormity gives rise to experiences of displacement, in some cases developing into experiences of the uncanny, danger or dread. This third field is often experienced by the actors involved in religious terms. 


\section{Us: Communitarian Radicalisation}

The first pathway identified is shared across a number of quite different experiences. One expression of communitarian radicalisation possesses the same building blocks as racism, centred on socially constructed 'disgust', and manifests the experiential structure of racism and hate crime. Here the imaginary of violence is one of cleansing, one we see starkly evident in the experience of people such as Aqsa Mahmood, a young woman who left Glasgow to travel to Syria in 2013. She lived her life on social media, this was a space both intimate and public, one that she shared with her 'fam'. In 2012 she encountered distant suffering, in this case the Israeli incursion into Gaza, and her social media timeline, once full of interchanges with her friends, begins to be populated by images of suffering and violence. Over a period of several months we see a clear transformation occur, evident in the way she experiences the world: first in terms of good and bad, then innocent and guilty, then in terms of the pure and the impure. At this latter point, the 'other', in this case Shia Muslims, become experienced as unclean, grotesque and ultimately a source of contamination. As she radicalises, much of her social media is taken up by communications setting out to establish how Shia Muslims are 'disgusting', an affective process that establishes a truth: 'you make me sick, therefore you are sickening' (Ahmed 2007). This is the anthropological structure of racism and hate crime, evident in the search for purity, a search that radicalises anxiety about disorder, experienced as dirt and the risk of contamination (Douglas, 1966). This fear of contamination is visceral, in that it does not work fundamentally at the level of ideas or cognitive propositions. While still a student, Mahmood tweets constantly about the impurity of Shia Muslims, focusing on ruptures of borders and barriers that ensure ontological and biological integrity. Her tweets are populated with claims that Shia Muslims have sex with animals, or that the Shia religious leader Ayatollah Khomeini approved sex with children. Her tweets, combining humour with graphic and disturbing images, suggest a kind of horror mixed with fascination, one where attraction and repulsion mix. It is the horror and disgust she constructs with others through the circulation of images, memes and jokes that allows Mahmood to embrace an imaginary of violence which she experiences in terms of purification or cleansing. So, while still at university in Scotland, she is retweeting calls for genocide (McDonald 2018).

Communitarian radicalisation also emerges among those who seek to disengage from criminal pathways that are experienced as fundamentally self-destructive. In a world of disorder and chaos, radicalisation involves a 
process of socialisation into a protective group which offers certainty and order. This mirrors the process where people join gangs (McDonald 1999) and is particularly evident in the experiential pathway of radicalisation in prison (Khosrokhavar 2013). In such cases, such as 'Jamal' who radicalised in prison and joined al-Mouhajiroun (McDonald 2018), the threat of violence is not only external, but internal - his own violence is dangerous and unpredictable. For him, radicalisation involves the passage into a group that offers structure and certainty, not only from the danger presented by others, but by his own potential for uncontrollable violence. In his case, just as joining a gang, radicalisation is fundamentally a passage from disorder to order. From this perspective, violence is a strategy to impose order in a world of disorder.

A different expression of communitarian radicalisation is evident among adolescent girls who radicalise as a group, as we see with a group of schoolgirls who travelled to Syria from London in February 2015. These girls live their lives on social media, where we encounter themes of vulnerability, beauty, truth and sisterhood. They live in a world of adolescent fusion, a way they are managing the passage from childhood to adulthood.

This way of managing this transition is different from that of gang membership. The gang is a means to impose order on disorder, a response to exclusion often experienced in school or neighbourhood. While many gangs become involved in criminality, involvement in criminality is often a means to be valued or included in a protective social group - evident in the role of violence in initiation rituals, a rite of passage that demonstrates loyalty to the group and its leaders (McDonald 1999).

The experience of these girls is equally one of transition from childhood to adulthood. However, there are few signs that they are excluded from school or neighbourhood, factors typically associated with the transition into a counter-world of the gang. Instead, the profile of these girls is one of 'good student'. Just as Mahmood, they are aware of distant suffering, and they too live their lives through social media. But they are younger than Mahmood, and their world is one where they share their love for each other as 'sisters'. However, they are leaving childhood, and with this comes the potential for relationships with boys, bringing with it jealousy that could fracture the love of the group for each other. However it is possible for the group to share one love, in this case the love of a powerful divine Other, a kind of fusional adolescent religious experience (Guitton 2015). This love will not shatter the sisterhood, on the contrary, it reinforces it. This helps us understand how these girls could travel to Syria, knowing that they will marry within weeks of arriving, and that the person they will marry is someone they don't know. It is precisely because they do not know 
their future husband that they can imagine marrying him: he is not an individual, he is a cypher, an expression of the God who is made real through the power of the Calif. This is not a love relationship that individuates. It is a love relationship that is not only consistent with the sisterhood, it takes the sisterhood to the next level. In this adventure of hijra they are embarking upon, the sisters can share everything, even their husband. In the words of another young woman who travelled to Syria, 'Being co wives with ur bestfriend is beautiful' (@GreenBirds22, Twitter 9 July 2014).

Not all girls follow this radicalisation pathway, but it is associated with a fusion experience typical of the strategies young people use to navigate from the safety of the family to the uncertainty of a wider social world. In this case, radicalisation is framed in terms of sisters sharing everything, even a husband. Hence the fundamental importance of travelling as a group, and an imaginary that cannot extend beyond this. One of the girls was interviewed by a British newspaper in 2019 after the fall of the Islamic State. Reflecting on the war in Syria and the possibility of death, she states 'I always thought if we did get killed, we would get killed together' (Loyd, 2019). The sisters would also share death.

You

A very different pathway emerges among gamers, hackers and among groups involved in criminality. In these cases, radicalisation is fundamentally experienced in terms of increased power, while violence is an act which reveals a truth about the victim.

Before he travelled to Syria, Junaid Hussain, the principal creator of the IS Cyber Caliphate, was convicted for hacking into the email of a staff officer of the then UK Prime Minister, as well as hacking a UK terrorist help line. Hussain had originally been involved in the 'Mujahideen Hacking Unit', a group involved in attacking Hindu nationalist sites in India. From there he extended to attacking poorly defended websites in order to post conspiracy theory messages, largely asserting that the United States was responsible for the September 11 attacks on the World Trade Centre and Pentagon ..$^{2}$ As leader of the hacker group TeaMp0isoN, Hussain defaced hundreds of websites, leaving messages celebrating his power, mastery and destiny, using the name 'TriCk' (McDonald 2018). In these actions, the fundamental affect involved is shared humour - Hussain celebrates his

2 See, for example (http://www.zone-h.com/mirror/id/126846110). 
skill and epic destiny as a hacker, while also revealing the weakness of his victim. When Hussain explained his path to hacking, well before his decision to travel to Syria and create the Cyber Califate, he describes discovering a world of hidden power, his discovery that the world is governed by secret forces, in particular the Illuminati, the Freemasons, and the Committee of 300 (McDonald 2018). His radicalisation alerts us to the pervasive presence of conspiracy theory among jihadists, embedded in an experiential structure of the hidden and the revealed. The person who has discovered such conspiracies is energised and transformed: they believe they have the courage to look at the world directly, they are not afraid to take the red pill (to evoke the language of contemporary neo-Nazis who describe their discovery of hidden Jewish plots to control the world at being 'red pilled') (Evans 2018). In a world shaped by conspiracies, the powerful are always hidden, and hence while Hussain's image was all over social media, he was always masked - the mask not being a means to hide his identity, but a technology of transformation. Masking allows Hussain to become someone else, defined by his power. Living in a world of conspiracy is to live in an affective state where hidden meaning is just out sight around the corner, of breathless excitement and of the certainty of one's own superiority to those who either are not smart enough to see the conspiracy, or lack the courage to look at the world as it is.

In the radicalisation of Junaid Hussain we encounter an experiential structure of power and pleasure that is also fundamental to criminal pathways that combine personal redemption with the sacralisation of war against society (Roy 2017). From this perspective, violence does not simply seek to kill, it seeks to humiliate, in order to reveal a truth about the victim. Hence the importance of communicating such violence, and involving others in this, even at distance. In such cases, the action mirrors that of the bully - their violence is public, and they seek to turn their audience into protagonists through humiliating the victim in a way that will get their audience to laugh. This underlines the fundamental dimension of humour in the communication associated with such violence - laughing together being a fundamental social activity. And here too we encounter the fundamental importance of humour in far-right extremism, built around laughter at the suffering and humiliation of the other, and the celebration of the power of the observer. The extensive role of humour and parody in violent extreme right networks, underlines the celebration of the power not to be affected by the suffering of the other (Greene 2019). Here we encounter a range of experiences all associated with a paradigm of 'gamification' (McDonald 2018), where radicalisation is lived through relationships of winning and losing, while violence is experienced as fundamentally revealing 
a truth about its victim - hence the importance of videoing and uploading images of the humiliation of the victim, laughing and taking pleasure in the suffering of the other.

In such cases, violence equally reveals a truth about the perpetratorhence the importance of filming the self, narcissism and a culture of fame. This was particularly evident in the case of Abdulhamid Aboud, the leader of the November 2015 attacks in Paris, who during his time in Syria wore a GoPro camera attached to his hat, and would upload images to his Twitter account each day to celebrate his exploits (McDonald 2018).

'

A quite different experience of radicalisation centres on experiences of selfhood. In this pathway, what counts is the 'I'. Here we encounter experiences all based around the idea of rupture with one's past, where violence is an imaginary that both destroys one's past and reveals a truth about oneself.

Such violence, as in the other examples we are discussing, is not limited to experience of radicalisation. The paradigm case is the school shooter, who seeks to fracture reality through the scale of violence. Here an imaginary of scale is fundamental - the violence is to be 'epic', so great that it will fracture reality itself, and in the process reveal the greatness of the protagonist. This violence is intoxicating, one where the protagonist can declare 'I am a god', a truth that will be revealed through the enormity of the killings they will undertake. This imaginary of greatness is not only associated with school shooters. It is evident in the narcissism of conspiracy theory (where once again only the most intelligent and most courageous can see truth).

The 'I' also emerges as central to a range of experiences shaped by themes of vastness and enormity. These were at the centre of the History of Humanity videos produced by Omar Diaby that proved so important in among the first wave of French people to travel to Syria, being extensively downloaded and discussed on jihadist websites (Thomson 2018). The constant theme in these breathless discussions is the vastness of the conspiracy that is behind world government, a conspiracy shaped by dark supernatural powers (jinn and the promise of the antichrist, the dajall). While based on extraordinary secrets, this world, as in all conspiracy theories, is made up of the day-to-day events that are fundamentally familiar. Diaby's videos, framed with threatening soundtracks and ominous colour palettes combined with blurred and distorted extracts from the television news, com- 
municate a world that is familiar, but at the same time fundamentally strange. To draw on Freud, this is the 'uncanny' - the familiar turned weird and threatening (Freud 1919/2003). All these experiences give rise to an affective state of fear and anxiety, a world in disorder and chaos, associated with an aesthetic experience more than a desire to construct a community of order. This same theme of vastness and insignificance, close to the Romantic experience of the sublime, recurs throughout jihadi culture.

We encounter another experience of ' $I$ ' in experiences of radicalisation. This is where death is not a means to cleanse the world through killing the other, as with Mahmood, but is a means to purify the self (Khosrokhavar 2014). In such cases, death not only obliterates the self, but the life one has led. We see this in Brahim Abdesalam's suicide bombing at the Comptoir Voltaire in Paris in the November 2015 attack, where he sets out to kill himself and the patrons in a bar. He does not run in shouting and threatening, seeking to instil fear in terror in those he will kill. As he quietly walks into the bar, no one even looks at him. He pauses, places his hands over his face, takes several breaths, and then detonates his suicide belt ${ }^{3}$. Only a month earlier he had been the manager of a bar in Brussels that had been closed by police on the ground that it was being used as a base to distribute drugs (McDonald 2018). This violence does not attempt to humiliate or terrify its victims. Abdesalam is not seeking to reveal their unworthiness through humiliating them. His violence is focused on the self.

\section{Far-Right Radicalisation}

The analytical categories that emerge in the analysis of jihadist radicalisation offer insight into the far-right radicalisation emerging in Europe, North America and the industrialised nations of the Pacific. Fundamentally different from the neo-Nazi street fighters of the 1980s, this radicalisation is framed by affects and imaginaries that have their origins in digitally mediated worlds.

The idea of livestreaming mass killing was first associated with European jihadists in Syria. But it also emerged at the same time on the image board 4Chan, where in 2014 a man uploaded images of his girlfriend who

3 The attack was filmed by the café security camera. Extracts from this film are widely available online, for example at (https:/video-streaming.orange.fr/tv/inedit-m6diffuse-l-explosion-de-brahim-abdeslam-au-comptoir-voltaire-CNT000001a3RJM.html). 
he had just strangled, commenting that this was much more difficult than in the movies (Nagle 2017: 27). In the case of 4Chan, such examples of streaming murder were first associated with groups describing themselves as 'robots', and later 'incels' (involuntarily celibates). Opposed to both feminism and non-whites, this imaginary of violence comes to be embraced by contemporary expressions of neo-Nazism, as a cohort left 4Chan to move to $8 \mathrm{Chan}$. This is fundamental to understand two far-right killings that took place in 2019: the March 2019 mass killing of people praying in two mosques in Christchurch, New Zealand, and the October 2019 attempted mass killing of people praying at a synagogue in Halle, Germany.

Both these attacks owe a significant debt to imaginaries of violence constructed by school shooters, which became increasingly visible on 4chan with the introduction of its $/ \mathrm{r}$ / (relationships) board, a board that came to be populated by the group we now call Incels. In October 2015 Chris Harper Mercer announced on 4Chan's / $\mathrm{r} /$ board that he was going to undertake a mass killing at a school on the next day (Nagle 2017: 26). Ideas about how to proceed were shared, with Harper Mercer at one point asking those in the discussion to 'keep me in your prayers'. Throughout the discussion he receives advice and support, one participant welcoming his declaration as the beginning of the 'beta uprising' (here 'beta' refers to 'beta males' who are not able to gain the affection of women). In the 'manifesto' that Harper Mercer distributed to his victims before killing them, he declares that he dies a virgin, evokes the Columbine killers, but he also evokes Satan as the source of his action, promising to return to life after his death as a vampire. He has previously explored the 'lost secrets of the Illuminati'. Similar references to Satanism and other expressions of the occult recur in the imaginary of neo-Nazi groups such as System Resistance Network in the United Kingdom, evoking the place of the occult in the Nazism during the fascist era (Staudenmaier 2014).

What is striking is the extent of themes that are shared by jihadist and far-right violence: racial disgust framed within an imaginary of purity and impurity; a desire for death of the self within a desire to fracture the real through the scale of violence; the vertigo of power associated with the discovery of hidden conspiracies and knowledge; fascination with the sublime, expressed in terms of attraction and repulsion. Humour plays a similar and fundamental communicative role in both jihadist and far-right extremism. Historically these themes have played an important role in farleft violent extremism as well. The leaders of the American Weather Underground were fascinated by the violence of Charles Manson's murderous cult (Varon 2004), while conspiracy theories around Jewish financial power retain a significant place in the imaginary of the far-left (Byford 2011). 


\section{My Name is Anon}

On October 9, 2019, the day of Yom Kippur, a 29-year old man attempted to attack a Jewish synagogue in the city of Halle, Germany, live streaming the attack from a camera he was wearing. Equipped with poorly constructed home-made explosives and weapons, he was unable to gain entry to the synagogue, and proceeded instead to kill two people he encountered - the first a woman who was walking past him in the street and admonished him for the disturbance he was making, the second victim was a patron in a kebab shop. He streamed the video of the attack from a camera he was wearing to a gaming platform. Immediately before attempting to enter the synagogue, the alleged killer directed his camera towards himself, and speaks to it:

' $\mathrm{Hi}$, my name is Anon. I think the Holocaust never happened. Femimism is the cause of the decline of the West which acts as a scapegoat for mass immigration. And the root of all these problems is the Jew. Would you like to be friends?' (archived video).

This brief statement captures critical dimensions of an experience of radicalisation. The attacker is speaking in English: he is not an ultranationalist, he is not defending a national identity. Something else happening.

The attacker begins by declaring 'My name is Anon'. The term 'Anon' refers to 4 Chan and 8 Chan. These are both anonymous discussion boards, where the website attributes 'Anon' as the 'name' or 'handle' to every person who posts to the site. Describing himself as 'Anon' signals that he is part of an online world, and that he is sharing his attack with that world. He posts livestream of the attack to an online gaming platform. He begins by an act of Holocaust denial, thus affirming his links with neo-Nazism. But why does he state that feminism is the source of what he sees as the decline of the West, and the cause of mass migration? This is because he believes that as a result of feminism, women refuse to have sex with men like him, and the resulting population decline is the source of mass immigration - leading, he believes, to the replacement of the white race. But how is it possible that the Jewish people are at the source of this decline? Because he believes that feminism is the product of Jewish intellectuals. This reflects a widespread campaign on alt-right social media that 'Feminism is a Jewish war on women', a theme widely repeated on neo-fascist online platforms.

The attacker also posted a manifesto online, where he refers to conspiracy tropes of ZOG - Zionist Occupied Government - and gamer culture, completing his manifesto with a 'jej', used in place of LOL. Throughout 
his manifesto his style of humour is self-deprecating, he is not presenting himself as a god wreaking vengeance.

While the attacker does not refer to his action as 'we', it was received and welcomed in those terms on 4Chan's /pol/ board. One poster writes:

'WE ARE MAKING PROGRESS

WE HAVE THE POWER TO KILL I.R.L.

WE ARE THE M.K. ULTRA NOW!

They will never laugh at us again, boys. We can wear our fedoras again, with pride!

Praise KEK!' (4Chan/pol/, 10 October 2019) ${ }^{4}$

The reference to 'never laugh at us again' and 'fedoras' evokes dimensions of Incel culture, being laughed at by others or wearing unfashionable fedora hats. The Halle attack is celebrated on 4Chan as reversing this stigma, an act through which 'we' are making progress, 'we' have the power to kill in real life, indeed 'we' are so powerful that we can be compared with what members of 4Chan believe to be the secret FBI mind control programme, M.K. Ultra. This poster also refers to 'KEK'. Originally a gamer expression for LOL emerging in World of Warcraft, in December 2017 KEK was transformed on 4Chan's /h/ or 'history' board into a mythical god, represented by Pepe the Frog, a figure that had become claimed by alt-right groups as their own. Not long after the creation of the god KEK, other participants in 4Chan created a country that the god KEK rules, calling it Kekistan, and imagining it inhabited by Kekistanis. Then on 4Chan a movement for the liberation of this fictional country developed. Over the following 12 months Kekistan became a central motif of a cluster of videos extending and developing principally on YouTube, rapidly expanding in scope, in part responding to the algorithm that builds links between themes across the platform. This has provided the basis for the expansion of Kekistan as an imaginary, a parody of liberation struggles, associated with the call to 'kill all normies' (Nagel 2017). The production and circulation of YouTube videos was central to this process, driven by what Emeline de Keulenaar describes as 'the ironic, trolling, countercultural online right' (2019: 2). Here we encounter a political project constructed in the language of irony and parody. While KEK emerged in a process of playing with mashup culture, and was not originally associated with Nazism, the link has now been forged, in particular through the creation of the flag of Kekistan, modelled

4 This conversation is archived at (https://archive.4plebs.org/pol/thread/229357532/ \#q229360881). 
on the warflag of Nazi Germany. This flag appeared at the Unite the Right demonstration in the United States, and also at pro-Bolsonaro rallies in Brazil.

An important current in the alt-right emerges from the world of gamers, with significant debts to the anti-feminist mobilisation referred to as 'gamergate' (Bezio 2018). Originating as a campaign against a victim of revenge porn, gamergate mobilised an opposition to political correctness, explicitly framing this as anti-feminist. This converged with Incel culture on shared digital platforms, where Incel appeals to violence against women often draw upon an imaginary of opposition to black men, presented as desired by women. It is the opposition to both women and non-whites that has been the basis for the convergence between Incels and white supremacism evident in the attempted massacre in Halle in October 2019.

Conspiracy theories play a role throughout these different pathways. There is a convergence with the experience of gaming, where the world is experienced in terms of multiple levels and hidden meanings. It was this convergence that allowed Junaid Hussain to move so easily from the world of gaming and involvement in Anonymous to the world of the jihad, evident in the way the Cyber Caliphate he created drew on the imaginary of Anonymous and its practice of 'doxing', a practice that involves posting private information to online sites (see McDonald 2015). Hussain's Islamic State Cyber Caliphate hacked into low security department store websites in the United States to identify the private addresses and phone numbers of US service personnel. It then posted this information online, calling on ISIS supporters in the US to go to these addresses and kill the occupants. These online posts were accompanied by the celebratory claim 'we know everything about you'. In Hussain's world, the powerful are invisible, while the powerless are exposed. The passage from a world devoted to secret meanings is also evident in the experience of Sally Jones who travelled with Hussain to Syria, who before embracing jihadism was a practitioner of alternative art and witchcraft (McDonald 2018), where the access to secret knowledge is a path to pleasure and power.

\section{Conclusion: Experiences of Radicalisation}

The radicalisation pathways we have explored in this chapter are not the result of manipulation or recruitment, but nor are they a reflection of archaic religious beliefs or the action of religious zealots. A great deal is shared between jihadist radicalisation and the alt-right that has become increasingly visible in Europe and North-America over the past decade. Just 
as the alt-right in Europe and North America evokes fears of collective disappearance in its narrative of 'great replacement' focusing on migration, so too imaginaries of death appear increasingly evident in communal tensions in Asia, most recently in Sri Lanka with rumours of sterilisation creams being applied to women's underwear by Muslim shopkeepers, claimed to be a means for Muslims to replace the Sinhalese population (Amarasingam 2019). The occult plays an important role in contemporary jihadism, mirroring the place of Satanism in Nazi subcultures in both North American and Europe. Similar themes of secret knowledge, vast conspiracies, immense danger and the promise of great power, all play an important role in the affective world sustaining the growth of jihadism in Asia, clearly evident in Indonesia (Fealy 2019).

Shifting our focus to a much closer engagement with actual experiences of radicalisation allows us to see clearly a new paradigm of violence emerging, one that is very different from the 'clandestine political violence' of the 1970s. What is very clear is the extent to which jihadist and alt-right extremism demonstrate similar practices and cultures: the importance of masking, an experiential structure built around the opposition between the hidden and the revealed; the experience of empowerment associated with the discovery of hidden knowledge. A closer engagement with experiences of radicalisation also highlights very different practices and imaginaries of violence. Here we encounter violence as cleansing, mirroring the same experiential structure as racism and hate crime; violence as revealing $a$ truth about the protagonist and/or the victim; and lastly, violence as fracturing reality (search for scale of killing, obliteration of self and other). From this perspective, radicalisation is not an experience of manipulation or recruitment, nor is it an expression of religious rejection of the world. Rather it is a form of practice or agency best understood as world-building. As such, radicalisation needs to be understood as an inherently political endeavour ${ }^{5}$, a form of political action best understood as a project of 'antidemocracy', or what Rosanvallon (2008) describes as politics in an age of distrust. The closer we get to actual experiences of radicalisation the more clearly we see the extent to which this involves embodied, communicative subjectivity, where actors produce and are sustained by an 'affective fabric' that is increasingly evident in digital sociality: practices of humour, exploit, fear, parody and irony, racism, celebrity, fascination with the occult, a contemporary dread of insignificance. It only through engaging with and

5 I would like to thank our editor, Dr. La Toya Waha, for underlining this dimension of radicalisation in her response to an earlier draft of this chapter. 
understanding such practices that we can hope to understand, and build responses to, the contemporary allure of radicalisation.

\section{References}

Ahmed, S. 2007. The Cultural Politics of Emotion. London: Routledge

Amarasingam, A. 2019. "Terrorism in the Teardrop Island: Understanding the Easter 2019 Attacks in Sri Lanka”, CTC Sentinel, 12 (5): 1-10.

Beauchamp, Z. 2018. "Incel, the Misogynist Ideology that Inspired the Deadly Toronto Attack Explained”. Vox, 25 April 2018.

Bezio, K. 2018. "Ctrl-Alt-Del: GamerGate as a Precursor to the Rise of the AltRight”. Leadership, 14 (5): 556-566.

Byford, J. 2011. Conspiracy Theories: A Critical Introduction. Basingstoke: Palgrave Macmillan.

De Keulenaar, E. 2019. The Rise and Fall of Kekistan: A Story of Idiomatic Animus as Told Through YouTube's Related Videos. (https://oilab.eu/the-rise-and-fall-of-kekistan-a-story-of-idiomatic-animus-as-told-through-the-youtube-recommender-system/).

Della Porta, D. 2013. Clandestine Political Violence. Cambridge: Cambridge University Press.

Douglas, M. 1966. Purity and Danger: An Analysis of Concept of Pollution and Taboo. London: Routledge and Kegan Paul.

Evans, R. 2018. "From Memes to Infowars: How 75 Fascist Activists Were RedPilled". Bellingcat, 11 October. (https:/www.bellingcat.com/news/americas/ 2018/10/11/memes-infowars-75-fascist-activists-red-pilled/).

Fealy, G. 2019. "Apocalyptic Thought, Conspiracism and Jihad in Indonesia". Contemporary Southeast Asia, 41, 1, 63-85.

Freud, S. 2003 [1919]. The Uncanny. London: Penguin.

Greene, V. 2019. "Deplorable Satire: Alt-Right Memes, White Genocide Tweets, and Redpilling Normies". Studies in American Humour, 5 (1): 31-69.

Guardian. 2019. "Usman Khan Attack at London Bridge: What We Know So Far". The Guardian, 30 November 2019. (https://www.theguardian.com/uk-news/ 2019/nov/30/usman-khan-attack-at-london-bridge-what-we-know-so-far).

Guitton, P. 2015. Adolescence et Djihadisme. Paris: L'Esprit du Temps.

Huntington, S. 1996. The Clash of Civilizations and the Remaking of the World Order. New York: Simon and Schuster.

Jenkins, B. 1975. "International Terrorism: a New Mode of Conflict". In: Carlton, D. and Schaerf, C., ed. International Terrorism and World Security, pp. 13-49. London: Croom Helm.

Juergensmeyer, M. 2017. Terror in the Mind of God: The Global Rise of Religious Violence. Los Angeles: University of California Press. 
Khosrokhavar, F. 2013. "Radicalisation in Prison: The French Case". Politics, Religion and Ideology, 14 (2): 284-306.

Koehler, D. 2019. "The Halle, Germany, Attack and the Evolution of the Far-Right Terror Threat”. CTC Sentinel, 12 (11): 14-20.

Kundnani, A. 2012. "Radicalisation: The Journey of a Concept". Race and Class, 54 (2): 3-25.

Loyd, A. 2019. "Shamima Begum: Bring Me Home, says Bethnal Green Girl Who Left to Join ISIS". The Times, 13 February 2019. (https:/www.thetimes.co.uk/ article/shamima-begum-bring-me-home-says-bethnal-green-girl-who-fled-to-joinisis-hgvqw765d).

McDonald, K. 1999. Struggles for Subjectivity: Identity, Action and Youth Experience. Cambridge: Cambridge University Press.

McDonald, K. 2013. Our Violent World: Terrorism in Society. Basingstoke: Palgrave.

McDonald, K. 2015. "From Indymedia to Anonymous: Rethinking Action and Identity in Digital Cultures”. Information, Communication and Society, 18 (8): 968-982.

McDonald, K. 2018. Radicalization. Cambridge: Polity.

Nagle, A. 2017. Kill All Normies: Online Culture Wars from 4Chan and Tumblr to Trump and the Alt-Right. Alresford: Zero Books.

Rosanvallon, P. 2008. Counter-Democracy: Politics in an Age of Distrust. Cambridge: Cambridge University Press.

Roy, O. 2017. Jihad and Death: The Global Appeal of Islamic State. London: Hurst.

Silber, M. and Bhatt, A. 2007. Radicalization in the West: The Homegrown Threat. New York: New York Police Department.

Staidenmaier, P. 2014. Between Occultism and Nazism: Anthroposophy and the Politics of Race in the Fascist Era. Leiden/Boston: Brill.

Thomson, D. 2018. The Returned: They Left to Wage Jihad, Now They're Back. Cambridge: Polity.

Varon, J. 2004. Bringing the War Home: The Weather Underground, the Red Army Faction, and Revolutionary Violence in the Sixties and the Seventies. Berkeley: University of California Press.

Vincent, E. and Chapuis, N. 2019. "Attaque à la Préfecture de Police: La Radicalisation de Mickaël Harpon n'avait pas été Signalée”. Le Monde, 7 October 2019. (https://www.lemonde.fr/societe/article/2019/10/07/la-radicalisation-de-mickaelharpon-n-avait-pas-ete-signalee_6014525_3224.html). 
